This paper is published in the open archive of Mid Sweden University

DIVA http://miun.diva-portal.org

with permission of the publisher

Citation for the peer-reviewed published paper:

Logenius L, Friman L, Agnemo R. The influence of temperature and moisture on the optical properties of cellulose in the presence of metal chlorides and glucuronic acid. Nordic Pulp \& Paper Research Journal. 2008;23(1):7280 .

URL to article at publishers site:

http://dx.doi.org/10.3183/NPPRJ-2008-23-01-p072-080 


\title{
The influence of temperature and moisture on the optical properties of cellulose in the presence of metal chlorides and glucuronic acid
}

\author{
Louise Logenius, Linda Friman and Roland Agnemo, Mid Sweden University, Sundsvall, Sweden
}

KEYWORDS: Cellulose, Glucuronic acid, Discoloration, Temperature, Calcium, Magnesium, Iron, HMF, Furfural

SUMMARY: The influence of $\mathrm{Mg}^{2+}, \mathrm{Ca}^{2+}, \mathrm{Fe}^{3+}$ ions and glucuronic acid on the dry and humid heat-induced (120$180^{\circ} \mathrm{C}$ ) discoloration of cotton linter sheets was investigated. The quantity of the added metal ions was similar to that of metal ions found in wood and pulp.

Heat-induced ageing $\left(120-150^{\circ} \mathrm{C}, \mathrm{pH} 5\right)$ under dry conditions caused only slight discoloration of the reference sheets and of the sheets impregnated with the metal ions. However, during ageing at $180^{\circ} \mathrm{C}$, the presence of $\mathrm{Mg}^{2+}$ ions accelerated the discoloration. An initial $\mathrm{pH}$ in the range of 3-8 had no great influence on the discoloration of the reference sheets, but a low $\mathrm{pH}$ in combination with $\mathrm{Mg}^{2+}$ ions increased the discoloration drastically. Under humid ageing conditions at $180^{\circ} \mathrm{C}(<30 \mathrm{~min})$, the sheets discolored approximately twice as much as under dry conditions; the difference in discoloration caused by the metal ions was less than in dry ageing.

Adding glucuronic acid to the sheets caused extensive discoloration under dry ageing conditions $\left(120-180^{\circ} \mathrm{C}\right)$, while $\mathrm{Ca}^{2+}$ and $\mathrm{Mg}^{2+}$ ions decreased the glucuronic acid induced discoloration. Under humid conditions $\left(180^{\circ} \mathrm{C}\right)$, however, $\mathrm{Mg}^{2+}$ and $\mathrm{Ca}^{2+}$ ions did not prevent the discoloration caused by glucuronic acid.

An increase in the absorption coefficient was observed at $285 \mathrm{~nm}$, most likely due to the formation of 5-hydroxymethylfurfural (HMF) and 2-furaldehyde (furfural). GC-MS analysis reveals increased formation of HMF in the sheets impregnated with $\mathrm{Mg}^{2+}$ ions. Degradation of the cellulose in which the alkaline earth metals act as Lewis acids is proposed.

\footnotetext{
ADDRESSES OF THE AUTHORS: Louise Logenius (louise.logenius@miun.se), Linda Friman (linda.friman@ sodra.com), Roland Agnemo (roland.agnemo@domsjoe.com): Mid Sweden University, Fibre Science and Communication Network, FSCN, Department of Natural Science, SE-851 70, Sundsvall, Sweden

Corresponding author: Louise Logenius
}

Knowledge of the behavior of cellulose material at high temperatures is important for many industrial processes, for example, in producing mechanical and chemical pulps and in producing materials containing lignocellulose fibers. High temperatures induce chemical changes in the wood components. The changes in reflectance and light absorption in the UV region give information about the formation of potential color precursors, leucochromophores. These can undergo further reactions forming colored substances, chromophores that are detectable in the visible region (Schmidt, Heitner 1993).

Chemical pulps consist almost exclusively of cellulose and hemicelluloses. Hexenuronic acid, which is formed during kraft cooking, is more pronounced in hardwood pulps due to the higher native xylan content (Hon,
Shiraishi 2001). Some of the hexenuronic acids remain after bleaching and may cause severe brightness reversion (Granström et al. 2001; Simão et al. 2005; Sevastyanova et al. 2006). Other constituents in carbohydrates such as carbonyls groups can also cause heat-induced discoloration of the pulp (Chirat, de la Chapelle 1999). Thermal treatment causes formation of furan compounds from carbohydrates in chemical and mechanical pulps (Forsskåhl et al. 2000).

Carbohydrates are generally degraded more slowly in alkali than in acid. The main degradation pathways of cellulose in alkali are the endwise peeling reaction and alkaline hydrolysis (Hon, Shiraishi 2001). The acid hydrolysis of cellulose and hemicelluloses is a rapid reaction that increases with increasing acid strength and temperature. The acid hydrolysis of cellulose (1) initially yields glucose (2), which can form 5-hydroxymethyl-furfural (3, HMF) (Fig 1, A). The acid hydrolysis of hemicelluloses containing furanoses yields furfural. The glucuronic acid unit in xylan reduces the hydrolysis rate under either alkaline or acidic conditions (Hon, Shiraishi 2001).

The rate of oxidation of carbohydrates depends on $\mathrm{pH}$, moisture, temperature, access to oxidizing agents, and the presence of transition metal ions (Williams et al. 1977; Shafizadeh, Bradbury 1979; Garves 1981; Bicchieri, Papa 1996; Kolar 1997; Hon, Shiraishi 2001; Calvini, Gorassini 2002; Selih et al. 2007). The oxidative degradation of cellulose is enhanced under alkaline conditions; the oxidation is accompanied by the formation of peroxide or peroxyl radicals (Shafizadeh, Bradbury 1979; Kolar 1997; Strlic et al. 2000). Oxidized glucose units in the cellulose chain are capable of further reactions, leading to the cleavage of the cellulose chain and the formation of colored compounds (Rapson, Corbi 1964; Luetzow, Theander 1974).

Thermal degradation of cellulose (1) at low to moderate temperatures yields 5-hydroxymethyl-furfural (3, HMF), which can decompose to form 2-furaldehyde (4, furfural) (Fig 1, B) (Emsley, Stevens 1994). Furfural also can be formed via levoglucosan (5) (Fig 1, C) (Fagerson 1969; Emsley, Stevens 1994; Li et al. 2005). Water evolves via the thermal degradation of carbohydrates; therefore, a hydrolytic scission route prevails over oxidative degradation at low or moderate temperatures under dry conditions (Withmore, Bogaard 1994; Scheirs et al. 2001).

Many primary carbohydrate degradation products are colorless but undergo further reactions yielding chromophores or colored complexes with transition metals (Singh et al. 1948; Czeipel 1960; Rapson, Corbi 1964; Luetzow, Theander 1974; Popoff Theander 1972, 1976).

HMF and furfural are colorless substances. However, 

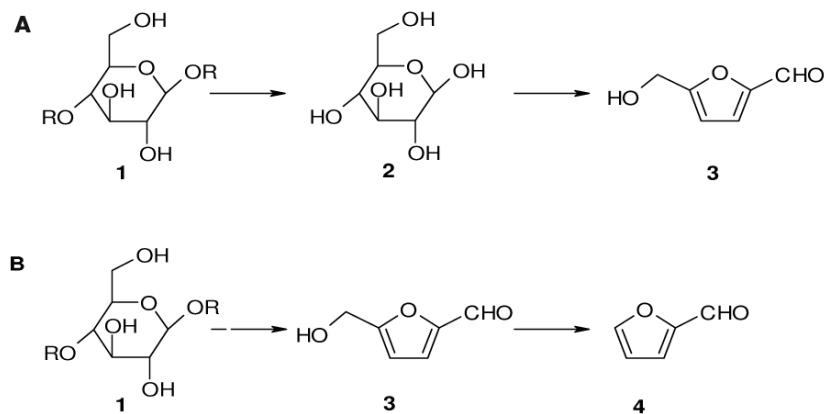

C

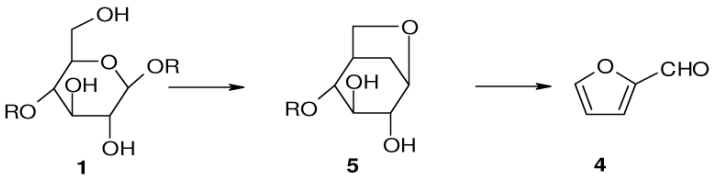

Fig 1. Different routes of cellulose (1) degradation.

A: Hydrolytic degradation: formation of 5-hydroxymethyl-furfural (HMF, 3) via glucose (2)

B: Thermal degradation: formation of HMF (3) and 2-furaldehyde (furfural, 4).

C: Thermal degradation: formation of levoglucosan (5) and furfural (4).

upon heating, HMF can cause severe discoloration (Singh et al. 1948; Forsskåhl et al. 2000) whereas furfural is more stable (Rapson, Corbi 1964).

Metal ions occur naturally in wood. Some of the most abundant metal ions in wood are sodium (10-100 ppm), manganese (10-100 ppm), iron (10-100 ppm), barium (10-100 ppm), zinc (10-100 ppm), magnesium (100-400 ppm), potassium (400-1000 ppm), and calcium (400$1000 \mathrm{ppm}$ ) (Stenius 2000). During the pulping processes, metal ions can be added to the pulp; these ions derive from process equipment, process water, and process chemicals (Bouchard et al. 1995; Lapierre et al. 1997; Friman et al. 2003).

Transition metal ions catalyze many chemical reactions in wood and pulp, and are therefore considered the most harmful metals in the pulping processes. Unlike transition metals, alkali, and alkaline earth metals are mostly considered beneficial or harmless to pulp and paper brightness (Czeipel 1960; Bicchieri, Papa 1996; Calvini, Gorassini 2002; Selih et al. 2007).

Lewis acids can also degrade cellulose; the metal ions form a complex with the glycosidic oxygen and the metal cation (Sarybaeva et al. 1991; Bicchieri, Papa 1996; Strlic et al. 2001).

In paper conservation, salts of alkaline earth metals are added to the paper to prevent discoloration caused by ageing. The effects of such treatments can be evaluated by accelerated ageing tests at high temperatures. The studies are mainly performed under neutral to alkaline conditions. The results of such studies are not unambiguous; some indicate that $\mathrm{Mg}^{2+}$ ions are a less effective stabilizer against paper discoloration and degradation than are $\mathrm{Ca}^{2+}$ ions, under both dry and humid ageing conditions (Williams et al. 1977; Lienardy, Van Damme 1990; Bansa 1998). Furthermore, $\mathrm{Mg}^{2+}$ ions can sometimes even accelerate brightness loss under accelerated ageing conditions (Kolar, Novak 1996).

Magnesium salts are sometimes added to the pulp for various reasons. Magnesium sulfate is added for stabili- zing hydrogen peroxide during bleaching, magnesium hydroxide is used instead of sodium hydroxide, and magnesium salts can also be added to avoid scaling (Colodette et al. 1989; He et al. 2004; Yu et al. 2004). It is therefore important to increase our knowledge how alkaline earth metals influences the color stability of the pulp.

In this paper, we elucidate how adding $\mathrm{Mg}^{2+}, \mathrm{Ca}^{2+}$, or $\mathrm{Fe}^{3+}$ ions to cellulose and adding glucuronic acid in combination with $\mathrm{Mg}^{2+}, \mathrm{Ca}^{2+}$, or $\mathrm{Fe}^{3+}$ ions to cellulose influences the discoloration induced by dry or humid heat ageing under slightly acidic conditions.

\section{Materials and Methods}

\section{Cellulose and impregnation chemicals}

Cotton linters with a cellulose content of $98 \%$ and a hemicellulose content of $2 \%$ were used. The pulp was essentially free of lignin and extractives. The carbohydrate composition of the cotton linter pulp after an acid wash was almost exclusively glucose (i.e., $>99 \%$ ).

Sodium hydroxide ( $\mathrm{NaOH}$, p.a.), hydrochloric acid ( $\mathrm{HCl}$, p.a.), ferric chloride $\left(\mathrm{FeCl}_{3}\right.$, p.a.), calcium chloride $\left(\mathrm{CaCl}_{2}\right.$, p.a. $)$, and magnesium chloride $\left(\mathrm{MgCl}_{2}\right.$, p.a.) were obtained from Riel-de Haën, D-Glucuronic acid (GlcA, p.a.) was obtained from Sigma, and 5-hydroxymethylfurfural (HMF, p.a.) were obtained from Aldrich.

\section{Acid wash}

Cotton linters were washed with $\mathrm{HCl}$ at $\mathrm{pH} 1.5$ and $1 \%$ pulp consistency for $2 \mathrm{~h}$ at $18^{\circ} \mathrm{C}$ and thereafter five times with Milli-Q water at the same pulp consistency. During the final washing stage, the pulps were soaked in the Milli-Q water for $30 \mathrm{~min}$ before being dewatered. The $\mathrm{pH}$ of the last filtrate was neutral.

\section{Impregnation}

To compare the effects of $\mathrm{Ca}^{2+}$ and $\mathrm{Mg}^{2+}$ ions on the heatinduced discoloration of the cellulose, the molar amount of added $\mathrm{Ca}^{2+}$ and $\mathrm{Mg}^{2+}$ ions was the same $(0.025$ mole $/ \mathrm{kg}$ ) in the cotton linter sheets. Thus, $\sim 600 \mathrm{ppm} \mathrm{Mg}^{2+}$ ions or $\sim 1000 \mathrm{ppm} \mathrm{Ca}^{2+}$ ions were added to the sheets. In contrast, the molar amount of added $\mathrm{Fe}^{3+}$ ions was much lower $\left(3.6 \times 10^{-4} \mathrm{~mole} / \mathrm{kg}\right)$, corresponding to $\sim 20 \mathrm{ppm} \mathrm{Fe}$ ions. The amount of added glucuronic acid was $\sim 1.20 \%$ (w/w).

The $\mathrm{pH}$ of the cotton linter suspension was adjusted to the appropriate $\mathrm{pH}(3,5$, or 8$)$ with $\mathrm{HCl}$ or $\mathrm{NaOH}$ and sheets with a grammage of approximately $30 \mathrm{~g} / \mathrm{m}^{2}$ were then produced in a laboratory sheet former.

After being dried at room temperature, the sheets were stored in a desiccator overnight before impregnation. The solutions used for impregnation were as follows: $\mathrm{CaCl}_{2}$ $(0.013 \mathrm{M}), \mathrm{FeCl}_{3}\left(5.2 \times 10^{-5} \mathrm{M}\right)$ or $\mathrm{MgCl}_{2}(0.012 \mathrm{M})$; or glucuronic acid (GlcA, $0.025 \mathrm{M}$ ); or glucuronic acid $(0.025 \mathrm{M})$ with added $\mathrm{FeCl}_{3}\left(3.8 \times 10^{-5} \mathrm{M}\right), \mathrm{CaCl}_{2}(0.013$ $\mathrm{M})$, or $\mathrm{MgCl}_{2}(0.012 \mathrm{M})$; or $\mathrm{HMF}(0.025 \mathrm{M})$; or HMF $(0.025 \mathrm{M})$ with added $\mathrm{FeCl}_{3}\left(3.8 \times 10^{-5} \mathrm{M}\right), \mathrm{CaCl}_{2}(0.013$ $\mathrm{M})$, or $\mathrm{MgCl}_{2}(0.012 \mathrm{M})$. 
The solutions were adjusted to the appropriate $\mathrm{pH}$ using hydrochloric acid or sodium hydroxide in order to obtain the same initial $\mathrm{pH}$. The sheets were placed on a clean polyethylene film; $3 \mathrm{~mL}$ of the impregnation solution were added to the sheets, which contained $\sim 0.285 \mathrm{~g}$ cellulose material. After $15 \mathrm{~min}$, the excess solution was removed by absorbing with blotting paper. The sheets were attached to the polyethylene film with adhesive tape and left to dry for $3 \mathrm{~h}$, after which they were placed in a desiccator overnight. Square sheets were cut from the laboratory sheets and the grammage was determined before the UV-VIS reflectance spectra were recorded.

\section{Analysis of metal content of the sheets}

The cotton linter reference sheets and the impregnated cotton linter sheets were analyzed for metals using ICPOES according to the procedure described in Friman et al. (2003).

\section{Analysis of glucuronic acid content}

The glucuronic acid content was analyzed according to Taylor and Buchanan-Smith (1992), with some modification.

First, $0.1 \mathrm{~g}$ samples of cellulose containing known amounts of glucuronic acid were prepared and treated according to the method for obtaining a calibration curve. A reference sample of untreated cellulose was also prepared.

Then, $0.1 \mathrm{~g}$ of glucuronic acid-impregnated sheet was heated with $2 \mathrm{~mL}$ of water in a sealed silica glass tube for $2 \mathrm{~h}$, after which $0.5 \mathrm{~mL}$ of the water extract was removed for analysis.

To the water extracts, $3 \mathrm{~mL}$ of a sulfuric acid solution (80\%) containing $\mathrm{NaBO}_{2} \times 4 \mathrm{H}_{2} \mathrm{O}(0.80 \mathrm{~g} / \mathrm{L})$ was added, along with $100 \mu \mathrm{L}$ of Carbazole in $95 \%$ ethanol. The tubes were carefully mixed and put in a water bath at $60^{\circ} \mathrm{C}$ for $2 \mathrm{~h}$. The solutions were analyzed using a Cary 100 Bio UV-Vis spectrophotometer (Varian, Palo Alto, $\mathrm{CA})$ at $530 \mathrm{~nm}$.

\section{pH measurements}

The measurements were made according to SCAN-P $14: 65$, except that a solution of $\mathrm{NaCl}(100 \mathrm{mM})$ was used instead of water.

\section{GC-MS analysis}

To analyze the degradation products of the aged cellulose samples, 100 or $200 \mathrm{mg}$ of the cellulose sample was put into a glass vial and heated to $60^{\circ} \mathrm{C}$ for 15 minutes. A headspace syringe (SPME) was used to adsorb the volatile substances. The analyses were carried out on a gas chromatograph that was connected to a single quadrupole mass spectrometer (Thermos, model DSQ). A Varian VF-5ms GC-column (30 m., 0.25 mm I.D., 0.25 $\mu \mathrm{m}$ film thickness) was used to separate the substances. The helium carrier gas flow rate was $1.0 \mathrm{ml} / \mathrm{min}$. The injector temperature was set at $230^{\circ} \mathrm{C}$ and the $\mathrm{GC}$ temperature program was as follows: $40^{\circ} \mathrm{C}(1 \mathrm{~min})-20^{\circ} \mathrm{C} / \mathrm{min}$ - $240^{\circ} \mathrm{C}$ ( $\left.5 \mathrm{~min}\right)$.

Relevant peaks were identified by MS by using electron impact $(70 \mathrm{eV})$ as ionization mode. The molecular ions of 5-hydroxymethyl-furfural $(\mathrm{m} / \mathrm{z}=126)$ and 2-furaldehyde $(\mathrm{m} / \mathrm{z}=96)$, which are two of several degradation products, were identified.

\section{Determining s- and k-values}

The reflectance spectra of the sheets were recorded using a Varian Cary 100 Bio UV-Vis spectrophotometer with a 70-mm-diameter integrating sphere coated with spectralon ${ }^{\circledR}$. The reflectance spectra were recorded in the 250-700 nm wavelength range. The two-background method (Schmidt, Heitner 1993; Pauler 2002) was used, and calculations using the Kubelka-Munk equations yielded the light scattering coefficient, $\mathrm{s}\left(\mathrm{m}^{2} / \mathrm{kg}\right)$, and light absorption coefficient, $\mathrm{k}\left(\mathrm{m}^{2} / \mathrm{kg}\right)$. Although the grammage of the sheets was quite high $\left(30 \mathrm{~g} / \mathrm{m}^{2}\right)$, the calculated s-values decreased smoothly from $250-700 \mathrm{~nm}$ in the figures presented here, so the sometimes high k-values were correctly determined.

\section{Heat-induced ageing of samples}

Reference cotton linter sheets and cotton linter sheets impregnated with $\mathrm{Ca}^{2+}, \mathrm{Mg}^{2+}$, or $\mathrm{Fe}^{3+}$ ions or with glucuronic acid and $\mathrm{Ca}^{2+}, \mathrm{Mg}^{2+}$, or $\mathrm{Fe}^{3+}$ ions were aged in a laboratory oven under dry conditions at 120,150 , or $180^{\circ} \mathrm{C}$ for $2.5,5,10,30,60,90,150$, and $210 \mathrm{~min}$. Reference sheets and sheets impregnated with $\mathrm{Mg}^{2+}$ ions or $1.20 \%$ glucuronic acid with a $\mathrm{pH} 3$ and 8 were aged at $180^{\circ} \mathrm{C}$ under dry conditions and for the same periods as described above.

Reference cotton linter sheets and cotton linter sheets impregnated with $\mathrm{Ca}^{2+}, \mathrm{Mg}^{2+}$, or $\mathrm{Fe}^{3+}$ ions or with glucuronic acid and $\mathrm{Ca}^{2+}, \mathrm{Mg}^{2+}$, or $\mathrm{Fe}^{3+}$ ions were also aged under humid conditions ( $\mathrm{pH}$ 5). The ageing experiments were performed in a chamber pressurized with steam at $180^{\circ} \mathrm{C}$ for 5,10 , and $30 \mathrm{~min}$. The sheets were placed in a desiccator to dry overnight before the reflectance spectra were recorded and the light scattering coefficients and light absorption coefficients were determined.

\section{Results and Discussion}

To compare the effects of $\mathrm{Ca}^{2+}$ and $\mathrm{Mg}^{2+}$ ions on the heatinduced discoloration of the cellulose, the molar amount of added $\mathrm{Ca}^{2+}$ and $\mathrm{Mg}^{2+}$ ions was the same $(0.025$ mole $/ \mathrm{kg}$ ). The molar amount of added $\mathrm{Fe}^{3+}$ ions was much lower $\left(3.5 \times 10^{-4} \mathrm{~mole} / \mathrm{kg}\right)$, because the iron content of wood is much lower. Thus, approximately $600 \mathrm{ppm} \mathrm{Mg}^{2+}$

Table 1. Amounts of $\mathrm{Ca}^{2+}, \mathrm{Mg}^{2+}, \mathrm{Fe}^{3+}$ ions and glucuronic acid (GlcA) in the sheets.a

\begin{tabular}{lcccc}
\hline Sample & $\begin{array}{c}\mathrm{GlcA} \\
(\%)\end{array}$ & $\begin{array}{c}\mathrm{Fe}^{3+} \\
(\mathbf{p p m})\end{array}$ & $\begin{array}{c}\mathrm{Ca}^{2+} \\
(\mathbf{p p m})\end{array}$ & $\begin{array}{c}\mathrm{Mg}^{2+} \\
(\mathbf{p p m})\end{array}$ \\
\hline Reference & & $4 \pm 0.6$ & $12 \pm 3.3$ & $1 \pm 0.3$ \\
$\mathrm{CaCl}_{2}$ & & $8 \pm 1.5$ & $905 \pm 30$ & $3 \pm 1.3$ \\
$\mathrm{FeCl}_{3}$ & & $20 \pm 1.8$ & $22 \pm 3.5$ & $4 \pm 0.6$ \\
$\mathrm{MgCl}_{2}$ & & $8 \pm 1.9$ & $20 \pm 5.9$ & $600 \pm 24$ \\
$\mathrm{GlcA}$ & $1.24 \pm 0.04$ & $6 \pm 1.0$ & $12 \pm 7.5$ & $4 \pm 3$ \\
$\mathrm{GlCACaCl}_{2}$ & $1.19 \pm 0.04$ & $8 \pm 1.0$ & $995 \pm 50$ & $63 \pm 2$ \\
$\mathrm{GlCAFeCl}_{3}$ & $1.18 \pm 0.04$ & $24 \pm 1.0$ & $24 \pm 1.0$ & $4 \pm 1$ \\
$\mathrm{GlCAMgCl}_{2}$ & $1 . .24 \pm 0.04$ & $9 \pm 1.0$ & $20 \pm 11$ & $600 \pm 50$ \\
\hline
\end{tabular}




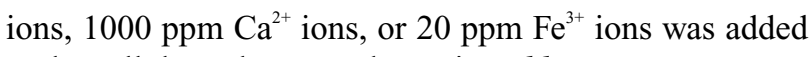
to the cellulose sheets as shown in Table I.

The unaged sheets impregnated with $\mathrm{Ca}^{2+}$ and $\mathrm{Mg}^{2+}$ ions or with glucuronic acid in combination with $\mathrm{Ca}^{2+}$ and $\mathrm{Mg}^{2+}$ ions displayed no significant increase in light absorption compared to that of the reference sheets. Adding $\mathrm{Fe}^{3+}$ ions or glucuronic acid in combination with $\mathrm{Fe}^{3+}$ ions to the sheets had a slight impact on the light absorption of the unaged sheets. Iron oxides or the formation of complexes between the iron ions and the glucuronic acid probably caused the increased light absorption.

The sheets were subjected to dry ageing at 120,150 , and $180^{\circ} \mathrm{C}$ and humid ageing at $180^{\circ} \mathrm{C}$ for different periods of time. The calculated light scattering coefficients, s, decreased smoothly over the measured region (250-700 $\mathrm{nm})$. This yields light absorption coefficients, $\mathrm{k}$, that can be used to make a reliable comparison between the sheets before and after heatinduced ageing.

\section{Influence of temperature and metals on the discoloration}

The initial $\mathrm{pH}$ of the sheets was 5 unless otherwise stated. The higher the temperature, the more pronounced was the ageing (Figs $2 a-c$ and $3 a-c$ ). The ageing of the
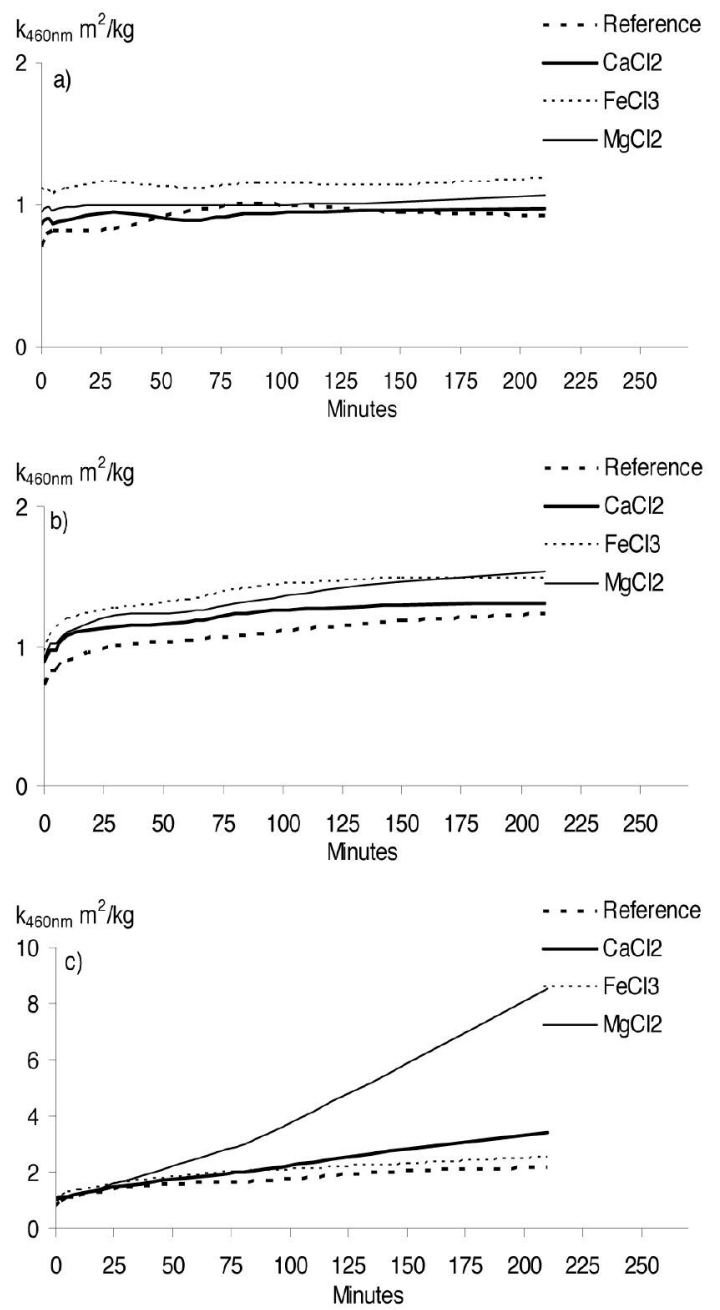

Figs 2a-c. Increase in light absorption coefficient, $k$, at $460 \mathrm{~nm}$, during ageing under dry conditions at 120,150 , and $180^{\circ} \mathrm{C}(\mathrm{a}, \mathrm{b}$, and $\mathrm{c}$, respectively) for different periods of time. sheets was studied at $460 \mathrm{~nm}$, because this is close to 457 $\mathrm{nm}$, the point at which the ISO brightness is measured.

When ageing at $120^{\circ} \mathrm{C}$ under dry conditions, there was almost no increase in absorption at $460 \mathrm{~nm}$ for either the reference sheets or the sheets impregnated with metal ions. For the sheets impregnated with glucuronic acid and those impregnated with glucuronic acid and $\mathrm{Ca}^{2+}$ or $\mathrm{Mg}^{2+}$ ions, only slight discoloration was obtained (Figs $2 a$ and $3 a$ ). The sheets impregnated with glucuronic acid and $\mathrm{Fe}^{3+}$ ions displayed greater discoloration than did the other examined samples (Fig $3 a$ ).

When ageing at $150^{\circ} \mathrm{C}$ under dry conditions, the discoloration was more pronounced for the sheets impregnated with glucuronic acid or with glucuronic acid in combination with metal chlorides than for the reference sheets or the sheets impregnated with only metal chlorides (Figs $2 b$ and $3 b$ ).

It is evident that the samples containing glucuronic acid in combination with $\mathrm{Ca}^{2+}$ and $\mathrm{Mg}^{2+}$ ions discolored significantly less than did the sheets impregnated with glucuronic acid or with glucuronic acid in combination with $\mathrm{Fe}^{3+}$ ions (Fig $3 b$ ). Glucuronic acid discolors rapidly when heated. The slightly higher absorption in the sheets with glucuronic acid and $\mathrm{Fe}^{3+}$ ions is probably due to the formation of colored complexes.
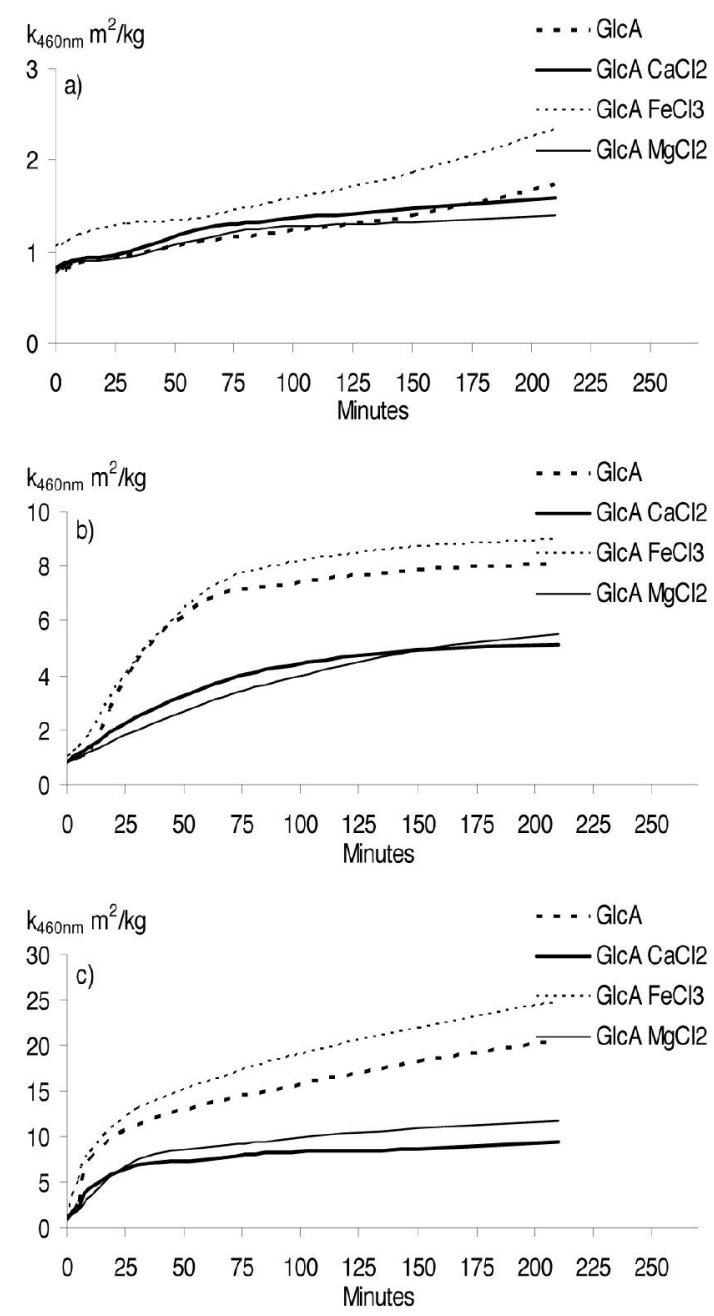

Figs 3a-c. Increase in light absorption coefficient, $k$, at $460 \mathrm{~nm}$, during ageing under dry conditions at 120,150 , and $180^{\circ} \mathrm{C}(\mathrm{a}, \mathrm{b}$, and $\mathrm{c}$, respectively) for different periods of time. 
When increasing the temperature to $180^{\circ} \mathrm{C}$, under dry conditions, the discoloration of all samples increased (Figs $2 c$ and $3 c$ ). The sheets impregnated with $\mathrm{Mg}^{2+}$ ions displayed much greater discoloration than did the reference sheets. The discoloration of the sheets impregnated with $\mathrm{Ca}^{2+}$ ions was not as obvious as that of the sheets impregnated with $\mathrm{Mg}^{2+}$ ions, though it was somewhat greater than in the reference sheets or the sheets impregnated with $\mathrm{Fe}^{3+}$ ions (Fig 2c). The discoloration caused by glucuronic acid decreased when $\mathrm{Ca}^{2+}$ and $\mathrm{Mg}^{2+}$ ions were present (Fig 3c).

This indicates that under certain conditions, in this case, dry heat-ageing under slightly acidic conditions and with access to oxygen, the presence of alkaline earth metals can negative affect the brightness stability of paper consisting mainly of cellulose.

\section{Influence of moisture and metals on discoloration}

The influence of moisture on the heat-induced ageing at $180^{\circ} \mathrm{C}$ was evaluated. Under humid ageing conditions, the discoloration of the sheets at $460 \mathrm{~nm}$ was significantly faster than under dry ageing conditions. This indicates the importance of the presence of water in chromophoreforming reactions. Under humid conditions, the metal ions have less influence on the discoloration than under dry conditions (Figs $4 a$ and $b$ ). Humid heat-induced ageing have been reported to be less dependent on the metal ions present than in dry heat-induced ageing (Bansa 1998).

The moisture-induced discoloration at $180^{\circ} \mathrm{C}$ was more than twice as high as the discoloration occurring under dry conditions after $30 \mathrm{~min}$, for both reference sheets and sheets impregnated with metal ions (Figs $2 c$ and $4 a$ ). The reference sheets and the sheets impregnated with glucuronic acid and alkaline earth metal ions displayed approximately equal discoloration after $30 \mathrm{~min}$ (Fig 4b). Alkaline earth metal ions do not prevent discoloration caused by glucuronic acid under humid ageing
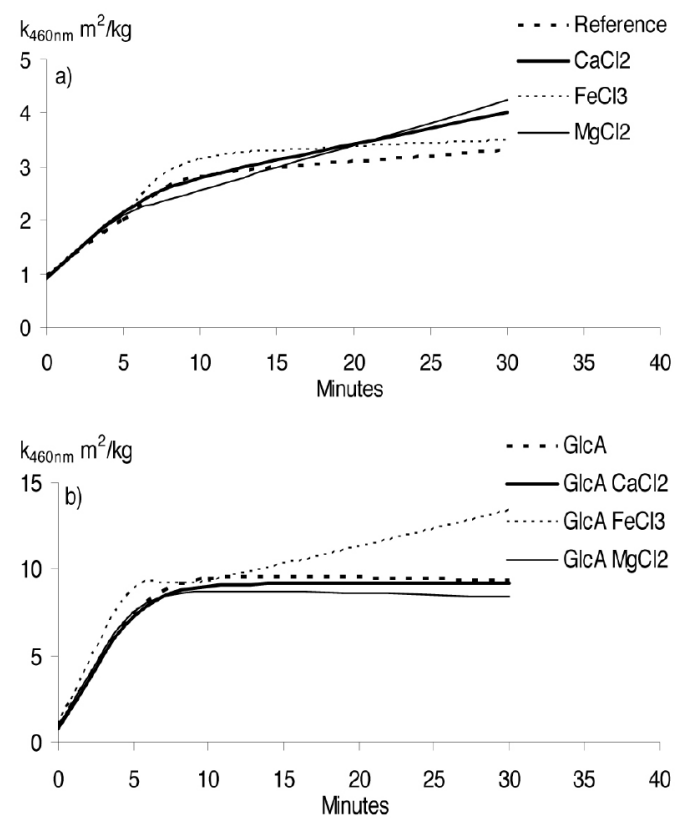

Figs 4a and b. Increase in light absorption coefficient, $\mathrm{k}$, at $460 \mathrm{~nm}$, during ageing under humid conditions at $180^{\circ} \mathrm{C}$ for different periods of time. conditions as effectively as under dry ageing conditions. The sheets impregnated with glucuronic acid and $\mathrm{Fe}^{3+}$ ions became significantly discolored.

\section{Changes in the UV region}

An absorption maximum was found at 285-290 nm when ageing all samples under both dry and humid conditions. This maximum can largely be attributed to the degradation products, furfural and HMF, formed from the cellulose (Fig 5). The higher the temperature, the more pronounced the maximum and the more furfural and HMF are produced.

HMF and furfural are potential color precursors, because they can form condensed structures upon heating. Such reactions probably account for most of the observed discoloration in the visible region (Popoff, Theander 1972, 1976; Forsskåhl et al. 2000).

When aged under dry and humid conditions, sheets

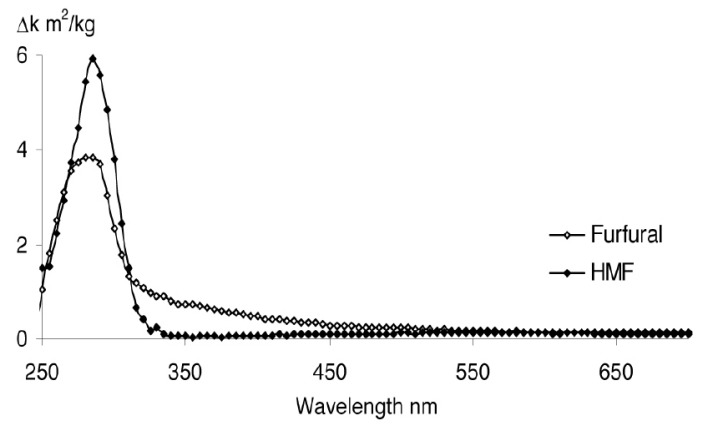

Fig 5. $\Delta \mathrm{k}$ spectra (impregnated sheet-unimpregnated sheet) of HMF and furfural. HMF has an absorption maximum at approximately $280 \mathrm{~nm}$ (Singh et al. 1948; Forsskåhl et al. 2000).

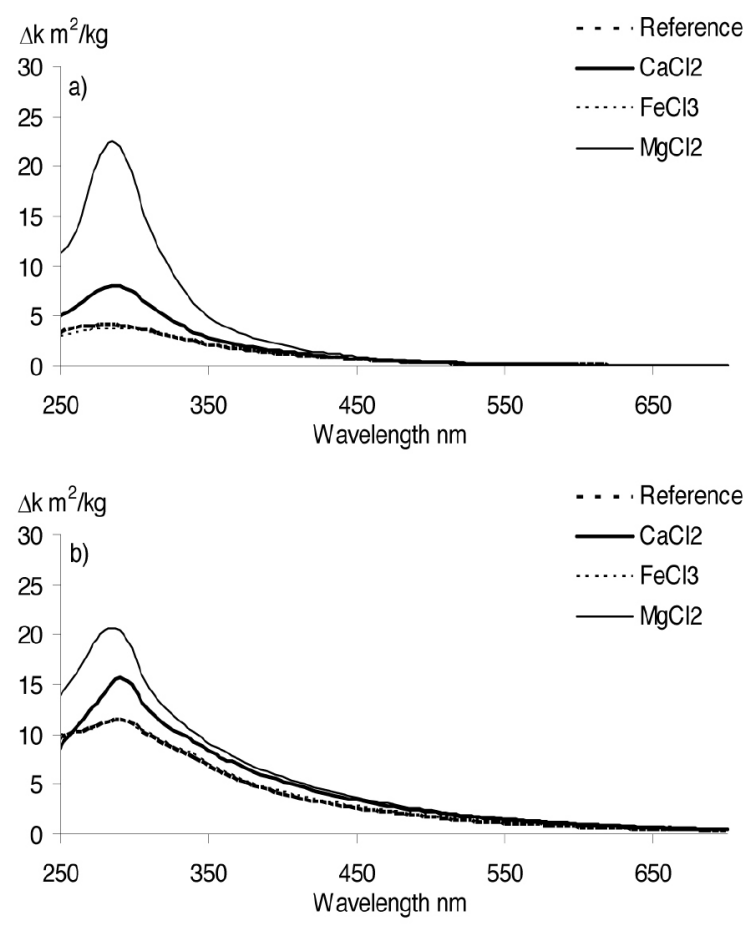

Figs $6 \mathrm{a}$ and $\mathrm{b} . \Delta \mathrm{k}$ spectra (aged sheet-unaged sheet) of cellulose impregnated with $\mathrm{Ca}^{2+}, \mathrm{Mg}^{2+}$, or $\mathrm{Fe}^{3+}$ ions aged under dry and humid conditions at $180^{\circ} \mathrm{C}$ for 30 minutes ( $a$ and $b$, respectively). 

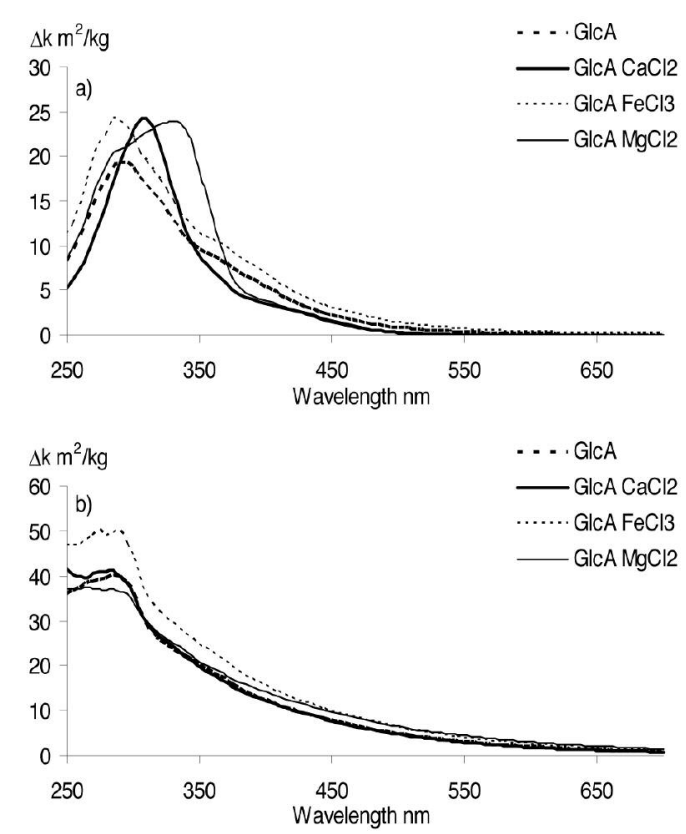

Figs $7 \mathrm{a}$ and b. $\Delta \mathrm{k}$ spectra (aged sheet-unaged sheet) of cellulose impregnated with glucuronic acid and with glucuronic acid in combination with $\mathrm{Ca}^{2+}, \mathrm{Mg}^{2+}$, or $\mathrm{Fe}^{3+}$ ions aged under dry and humid conditions at $180^{\circ} \mathrm{C}$ for 5 minutes (a and b, respectively).
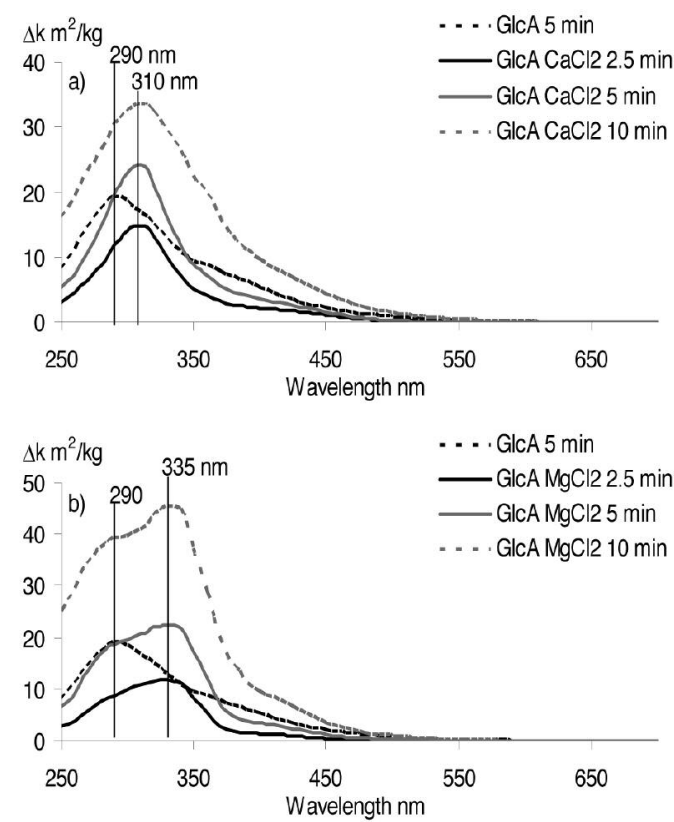

Figs $8 \mathrm{a}$ and b. $\Delta \mathrm{k}$ spectra (aged sheet-unaged sheet) of cellulose impregnated with glucuronic acid and glucuronic acid in combination with $\mathrm{Ca}^{2+}$ (a) or $\mathrm{Mg}^{2+}$ (b) ions aged under dry conditions at $180^{\circ} \mathrm{C}$ for different periods of time.

impregnated with $\mathrm{Mg}^{2+}$ and $\mathrm{Ca}^{2+}$ ions displayed spectra of similar shapes, except that sheets impregnated with $\mathrm{Ca}^{2+}$ ions yielded lower k-values (Figs $6 a$ and $b$ ). This indicated that the sheets impregnated with $\mathrm{Mg}^{2+}$ and $\mathrm{Ca}^{2+}$ ions react in a similar manner.

The shapes of the spectra of the reference sheets and the sheets impregnated with $\mathrm{Fe}^{3+}$ ions were quite similar. One explanation is that the amounts of $\mathrm{Fe}^{3+}$ ions were too low to cause any significant changes in the light absorption coefficient (Figs $6 a$ and $b$ ).

The absorption in the visible region is slightly higher for sheets impregnated with glucuronic acid or with glucuronic acid and $\mathrm{Fe}^{3+}$ ions than for sheets impregnated
Table 2. pH of reference sheets, metal-ion-impregnated sheets, and sheets impregnated with glucuronic acid or glucuronic acid and metal chlorides, unaged and aged under dry conditions at $180^{\circ} \mathrm{C}$ for $2.5 \mathrm{~h}$.

\begin{tabular}{|c|c|c|}
\hline Sample & Unaged samples & $180^{\circ} \mathrm{C} 2.5 \mathrm{~h}$ \\
\hline Reference & 5.3 & 5.2 \\
\hline $\mathrm{CaCl}_{2}$ & 5.4 & 5.5 \\
\hline $\mathrm{FeCl}_{3}$ & 5.2 & 5.3 \\
\hline $\mathrm{MgCl}_{2}$ & 5.4 & 5.3 \\
\hline GlcA & 5.2 & 5.3 \\
\hline $\mathrm{GlcACaCl}_{2}$ & 5.7 & 5.5 \\
\hline $\mathrm{GlcAFeCl}_{3}$ & 5.2 & 5.3 \\
\hline $\mathrm{GlcAMgCl}_{2}$ & 5.6 & 5.4 \\
\hline
\end{tabular}
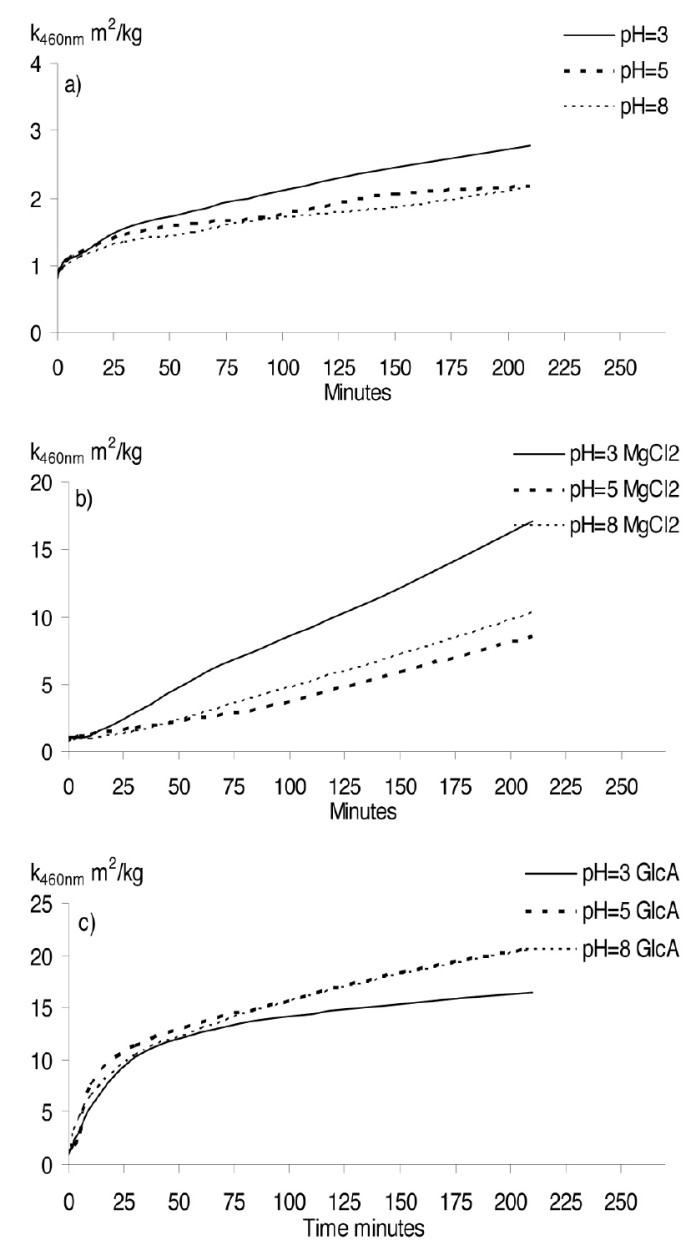

Figs 9a-c. Increase in light absorption coefficient, k, at $460 \mathrm{~nm}$, during ageing under dry conditions at $180^{\circ} \mathrm{C}$. Reference sheets, sheets impregnated with $\mathrm{Mg}^{2+}$ ions, and sheets impregnated with glucuronic acid ( $a, b$, and $c$, respectively) at different initial $\mathrm{pH}$.

with glucuronic acid and $\mathrm{Mg}^{2+}$ or $\mathrm{Ca}^{2+}$ ions when aged under dry conditions (Fig 7a). When ageing under dry conditions, the presence of $\mathrm{Mg}^{2+}$ or $\mathrm{Ca}^{2+}$ ions decreases the discoloration caused by the glucuronic acid (Fig 7a); this effect cannot be observed under humid conditions (Fig 7b). The moisture is evidently an important factor controlling the discoloration of cellulose and glucuronic acid.

For the sheets impregnated with glucuronic acid and $\mathrm{Mg}^{2+}$ or $\mathrm{Ca}^{2+}$ ions, gave rise to absorption maxima shifted towards longer wavelengths in the UV region than for sheets impregnated with only glucuronic acid when aged under dry conditions (Figs $8 a$ and $b$ ). 

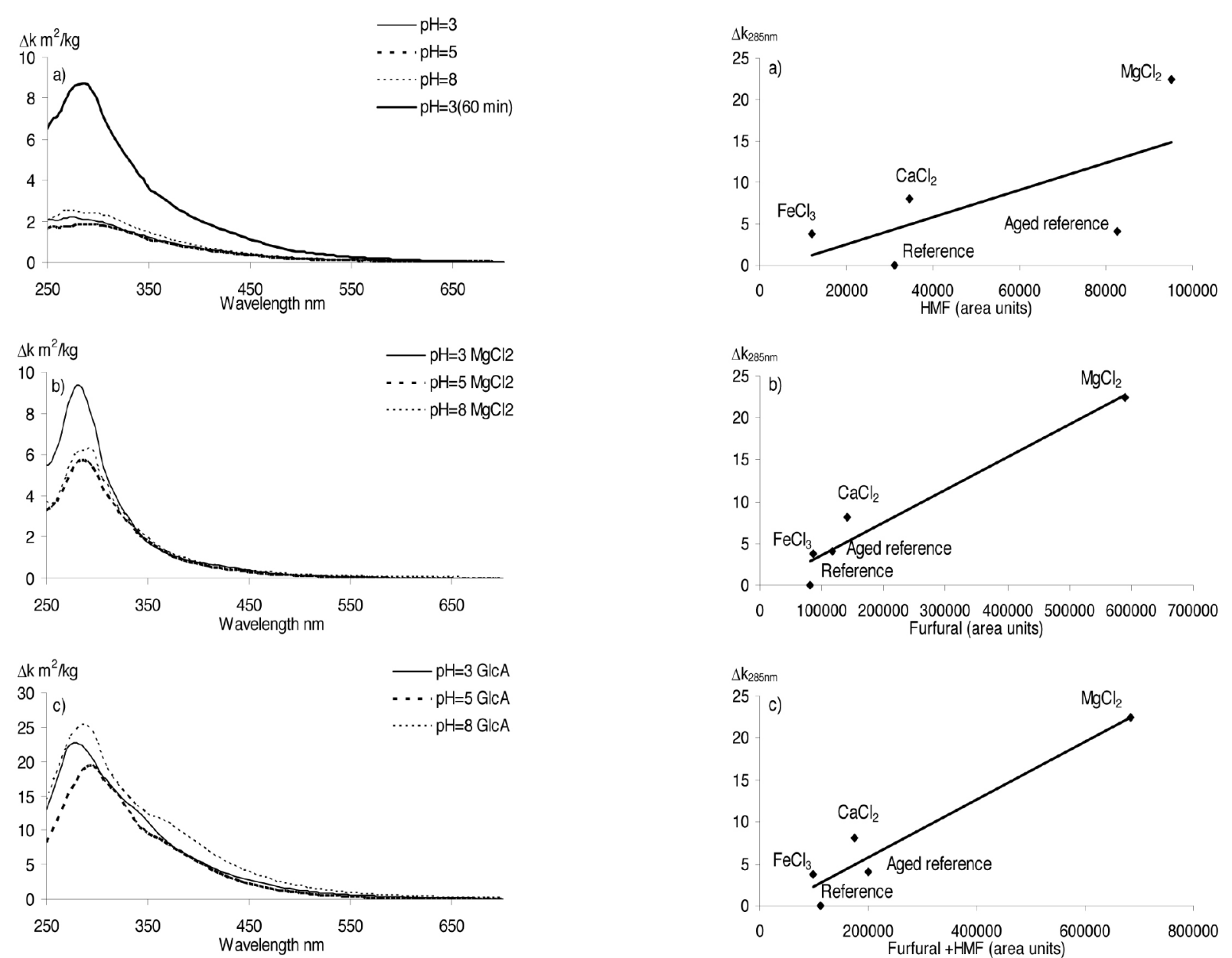

Fig 10a-c. $\Delta \mathrm{k}$ spectra (aged sheet-unaged sheet) of reference sheets, sheets impregnated with $\mathrm{Mg}^{2+}$ ions, and sheets impregnated with glucuronic acid $(\mathrm{a}, \mathrm{b}$, and $\mathrm{c}$, respectively) at different initial $\mathrm{pH}$ s, aged under dry conditions at $180^{\circ} \mathrm{C}$ for 30 minutes.

\section{pH measurements}

To observe any change in $\mathrm{pH}$ accompanying the color formation, $\mathrm{pH}$ measurements were made on the samples. No significant change in $\mathrm{pH}$ was observed after $2.5 \mathrm{~h}$ of ageing at $180^{\circ} \mathrm{C}$ (see Table 2 ). Thus, dry heat ageing had no significant effect on the $\mathrm{pH}$.

\section{Influence of pH}

In the investigations described so far, the sheets had an initial $\mathrm{pH}$ of 5 . To evaluate the influence of $\mathrm{pH}$, reference sheets were made at $\mathrm{pH} 3$ and 8 . Sheets impregnated with $\mathrm{Mg}^{2+}$ ions or glucuronic acid at $\mathrm{pH} 3$ and 8 were aged under dry conditions at $180^{\circ} \mathrm{C}$.

Fig $9 a$ shows that only a small difference in the absorption at $460 \mathrm{~nm}$ was observed between $\mathrm{pH} 3$ and 8 for the cotton linter reference sheets. However, adding $\mathrm{Mg}^{2+}$ ions increased the discoloration of the cotton linter sheets at all pH levels. At pH 3, the discoloration was considerable (Fig $9 b)$. The $\mathrm{pH}$ had, however, a small effect on the ageing of sheets impregnated with glucuronic acid (Fig 9c).

\section{Changes in the UV region}

No pronounced absorption maximum at $285 \mathrm{~nm}$ was detected after $30 \mathrm{~min}$ for the reference sheets with an initial $\mathrm{pH}$ of 3 or 8 , but after $60 \mathrm{~min}$ the absorption at 290 $\mathrm{nm}$ increased for sheets with an initial pH of 3 (Fig 10a). An increase in the $\Delta \mathrm{k}$ value at the adsorption maximum

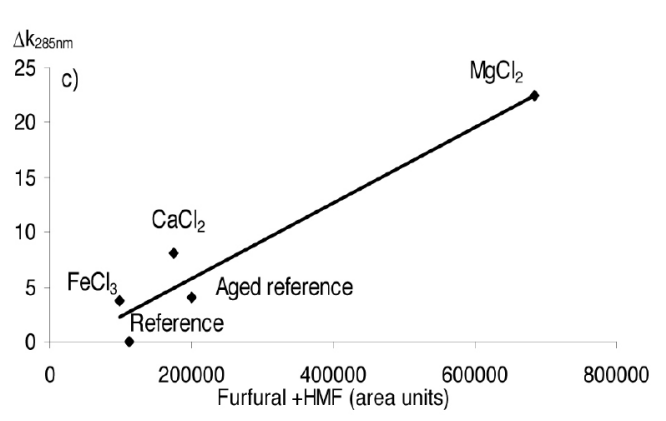

Figs 11a-c. Correlation between the $\Delta \mathrm{k}_{285 \mathrm{~mm}}$ of reference sheets and sheets impregnated with $\mathrm{Ca}^{2+}, \mathrm{Mg}^{2+}$, or $\mathrm{Fe}^{3+}$ ions aged under dry conditions at $180^{\circ} \mathrm{C}$ for 30 minutes and the formation of HMF, furfural and HMF + furfural, respectively.

at $285 \mathrm{~nm}$ was also observed in the presence of $\mathrm{Mg}^{2+}$ ions (Fig 10b).

Fig $10 \mathrm{c}$ shows the spectra of the sheets impregnated with glucuronic acid with an initial $\mathrm{pH}$ of 3,5 , or 8 . The absorption maximum in the UV region shifts towards longer wavelengths as $\mathrm{pH}$ increases.

\section{GC-MS analysis}

The absorption spectra indicated increased absorption at $285 \mathrm{~nm}$, which can be related to HMF and furfural formation. By plotting the change in absorption against the areas obtained using GC-MS analysis, it is possible to obtain a correlation between them. $\mathrm{Mg}^{2+}$ ions, which produced the highest light absorption at $285 \mathrm{~nm}$, also gave rise to the most HMF and furfural (Figs 11a-c).

The amount of HMF versus $\Delta \mathrm{k}_{285 \mathrm{~nm}}$ indicates that more HMF is produced when $\mathrm{Mg}^{2+}$ ions are present than in the aged reference (Fig 11a). The smaller amount of HMF in the sample containing $\mathrm{Fe}^{3+}$ ions may be due to increased decomposition of the HMF to furfural as proposed by Garves (1981). However, other degradation products may also be formed.

Fig $11 b$ shows that addition of $\mathrm{Ca}^{2+}$ and $\mathrm{Mg}^{2+}$ ions increase the furfural formation compared to the reference. The sum of HMF and furfural versus $\Delta \mathrm{k} 285 \mathrm{~nm}$ also correlates fairly well (Fig 11c). 
Table 3. Amount (area units $\times 10^{-3}$ ) of HMF and furfural. (I) Reference sheets and sheets impregnated with $\mathrm{Ca}^{2+}, \mathrm{Mg}^{2+}$, or $\mathrm{Fe}^{3+}$ ions. (II) Sheets impregnated with HMF; or HMF with added $\mathrm{Ca}^{2+}, \mathrm{Mg}^{2+}$, or $\mathrm{Fe}^{3+}$ ions. All sheets (I and II) were aged under dry conditions at $180^{\circ} \mathrm{C}$ for 30 minutes.

\begin{tabular}{lcccc}
\hline Sample & $\begin{array}{c}\text { HMF } \\
\text { (I) }\end{array}$ & $\begin{array}{c}\text { Furfural } \\
\text { (I) }\end{array}$ & $\begin{array}{c}\text { HMF } \\
\text { (II) }\end{array}$ & $\begin{array}{c}\text { Furfural } \\
\text { (II) }\end{array}$ \\
\hline Ref. (unaged) & 31 & 81 & n.a. ${ }^{1}$ & n.a. ${ }^{1}$ \\
Ref. (aged) & 83 & 117 & 6979 & 305 \\
$\mathrm{CaCl}_{2}$ & 35 & 141 & 3886 & 351 \\
$\mathrm{FeCl}_{3}$ & 12 & 86 & 2205 & 142 \\
$\mathrm{MgCl}_{2}$ & 95 & 590 & 3773 & 789 \\
\hline
\end{tabular}

n.a. $=$ not available

HMF or; $\mathrm{HMF}$ and $\mathrm{Ca}^{2+}, \mathrm{Mg}^{2+}$, or $\mathrm{Fe}^{3+}$ ions were added to the sheets and the sheets were aged under dry conditions at $180^{\circ} \mathrm{C}$ for 30 minutes (Table 3). The amount of HMF is decreased and the amount of furfural is increased if $\mathrm{Ca}^{2+}$ or $\mathrm{Mg}^{2+}$ ions are present (Table 3, II). This indicates an increased decomposition of HMF to furfural caused by alkaline metal ions. If $\mathrm{Fe}^{3+}$ ions are present a decrease in both HMF and furfural is displayed. This may be due to degradation of the HMF to other products such as levulinic acid (Fengel, Wegener 1989).

Several pathways lead to the formation of $\mathrm{HMF}$ and furfural, Fig 1 . During ageing at $180^{\circ} \mathrm{C}$ under dry conditions, acid hydrolysis (Fig 1, A) and thermal degradation (Fig 1, B) together with oxidation of the cellulose are the most likely pathways.

Although the experiments were performed in a dry oven, the samples contained both physically and chemically absorbed water (Scheirs et al. 2001). The amount of water released during heat-induced ageing may be enough for a hydrolytic reaction to take place.

The higher amount of HMF in the samples containing $\mathrm{Mg}^{2+}$ ions suggests that complexes form between the cation and the glucose unit, leading to a degradation reaction promoted by the cation acting as a Lewis acid. Strlic et al. (2001) suggest the formation of complexes between alkaline earth metal ions and the glucosidic oxygen. The complexing ability of the alkaline earth metal ions correlates with the electronegativity. The formation of complexes between alkaline earth metal ions and the $\mathrm{O}-1-\mathrm{H}$ and $\mathrm{O}-2-\mathrm{H}$ of the glucose has also been proposed by Tajmir-Riahi (1988). Lewis-acid-promoted cleavage of the cellulose chain has been proposed by Sarybaeva et al. (1991). The increased amount of furfural in the sheets with $\mathrm{Mg}^{2+}$ and $\mathrm{Ca}^{2+}$ ions indicates that the decomposition of HMF is promoted.

It is obvious that the $\mathrm{Mg}^{2+}$ and $\mathrm{Ca}^{2+}$ ions play an important role in discoloring the cellulose material and in forming $\mathrm{HMF}$ and furfural.

\section{Conclusions}

Moisture is an important factor controlling the heat-induced discoloration. Adding $\mathrm{Mg}^{2+}$ and $\mathrm{Ca}^{2+}$ ions to cotton linter cellulose accelerated the heat-induced discoloration under dry conditions at $180^{\circ} \mathrm{C}$, at an initial $\mathrm{pH}$ of 5 . Adding $\mathrm{Mg}^{2+}$ ions increased the discoloration drastically at $\mathrm{pH} 3$ compared to at $\mathrm{pH} 5$ and 8 .

Adding $\mathrm{Mg}^{2+}$ and $\mathrm{Ca}^{2+}$ ions to cotton linter sheets impreg- nated with glucuronic acid with an initial $\mathrm{pH}$ of 5 decreases the discoloration caused by the heat ageing of glucuronic acid. Under humid conditions, the positive effect of $\mathrm{Mg}^{2+}$ and $\mathrm{Ca}^{2+}$ ions on the discoloration caused by glucuronic acid was lost.

Addition of $\mathrm{Mg}^{2+}$ ions to the sheets increased the formation of HMF. The alkaline earth metal ions form complexes with the glucose unit. This leads to degradation of cellulose and formation of HMF. $\mathrm{Mg}^{2+}$ ions are suggested to acts as Lewis acids. Furfural is formed in large amounts in the sheets containing $\mathrm{Mg}^{2+}$ and $\mathrm{Ca}^{2+}$ ions. If $\mathrm{Fe}^{3+}$ ions are present a decrease in both $\mathrm{HMF}$ and furfural is displayed which may be due to formation of other degradation products such as levulinic acid.

\section{Acknowledgements}

Financial support from Mid Sweden University, FSCN, the Bo Rydin Foundation, the Knowledge Foundation, and EU Objective 1 is gratefully acknowledged. Thanks are also due to Domsjoe Fabriker AB and SCA Graphic Research AB for technical support. We thank Dr. Magnus Paulsson for his valuable comments.

\section{Literature}

Bansa, H. (1998): Aqueous deacidification - with calcium or magnesium? Restaurator, 19(1), 1-40.

Bicchieri, M. and Papa, S. (1996): The degradation of cellulose with ferric and cupric ions in a low-acid medium, Restaurator, 17(3), 165-183.

Bouchard, J., Nugent, H.M. and Berry, R.M. (1995): A comparison between acid treatment and chelation prior to hydrogen peroxide bleaching of kraft pulp, J. Pulp Paper Sci. 21(6), J203-208.

Calvini, P. and Gorassini, A. (2002): The degrading action of iron and copper on paper. A FTIR-deconvolution analysis, Restaurator, 23(4), 205-221.

Chirat, C. and de la Chapelle, V. (1999): Heat- and light-induced brightness reversion of bleached chemical pulps, J. Pulp Paper Sci. 25(6), 201-205.

Colodette, J.L., Rothenberg, S. and Dence, C.W. (1989): Factors affecting hydrogen peroxide stability in the brightening of mechanical and chemimechanical pulps. Part III: Hydrogen peroxide stability in the presence of magnesium or combinations of stabilizers, J. Pulp Paper Sci. 15(2), J45-50.

Czeipel, T.P. (1960): The influence of selected metal traces on the color and color stability of purified cotton linters, Tappi, 43(4), 289-299.

Emsley, A.M. and Stevens, G.C. (1994): Kinetics and mechanisms of the lowtemperature degradation of cellulose, Cellulose, 1(1), 26-56.

Fagerson, I.S. (1969): Thermal degradation of carbohydrates: a review, J. Agr. Food Chem. 17(4), 747-750.

Fengel, D. and Wegener, X. (1989): Wood Chemistry, Ultrastructure, Reactions, Walter de Gruyter, New York, NY, USA, pp 269-295.

Forsskåhl, I., Tylli, H. and Olkkonen, C. (2000): Participation of carbohydratederived chromophores in the yellowing of high-yield and TCF pulps, J. Pulp Paper Sci. 26(7), 245-249.

Friman, L., Logenius, L., Agnemo, R. and Högberg, H.-E. (2003): Comparison of metal profiles in thermomechanical pulping processes in which either hydrogen peroxide or dithionite bleaching is used, Paperi Puu, 85(6), 334-339.

Garves, K. (1981): Dehydration and oxidation of cellulose hydrolysis products in acidic solution, J. Wood Chem. Technol. 1(2), 223-235.

Granström, A., Eriksson, T., Gellerstedt, G., Rööst, C. and Larsson, P. (2001): Variables affecting the thermal yellowing of TCF-bleached birch kraft pulps, Nord. Pulp Paper Res. J. 16(1), 18-23.

He, Z., Wekesa, M. and Ni, Y. (2004): Pulp properties and effluent characteristics from the $\mathrm{Mg}(\mathrm{OH})_{2}$-based peroxide bleaching process, Tappi J. 3(12), 27-31.

Hon D.N.-S. and Shiraishi N. (2001): Wood and Cellulosic Chemistry, Marcel Dekker Inc, New York, NY, USA, pp 443-445, 450-456, 470-478, 493-497, 882886,889 .

Kolar, J. (1997): Mechanism of autoxidative degradation of cellulose, Restaurator, 18(4), 163-176. 
Kolar, J. and Novak, G. (1996): Effect of various deacidification solutions on the stability of cellulose pulps, Restaurator, 17(1), 25-31.

Lapierre, L., Paleologou, M., Berry, R.M. and Bouchard, J. (1997): The limits of metal removal from kraft pulp by acid treatment, J. Pulp Paper Sci. 23(11), J539-542.

Li, J., Henriksson, G. and Gellerstedt, G. (2005): Carbohydrate reactions during high-temperature steam treatment of aspen wood, Appl. Biochem. Biotechnol. 125(3), 175-188.

Lienardy, A. and Van Damme, P. (1990): Practical deacidification, Restaurator, 11(1), 1-21.

Luetzow, A.E. and Theander, 0. (1974): 6-Aldehydocelluloses - thermal instability, Beta-elimination and acid hydrolysis, Svensk Papperstidning, 77(9), 312-318. Pauler, N. (2002): Paper Optics, AB Lorenzen and Wettre, Kista, Sweden, pp 23-41. Popoff, T. and Theander, 0. (1972): Formation of aromatic compounds from carbohydrates. Part 1. Reaction of D-glucuronic acid, D-galacturonic acid, D-xylose, and L-arabinose in slightly acidic, aqueous solution, Carbohydr. Res. 22(1), 135-149.

Popoff, T. and Theander, 0. (1976): Formation of aromatic compounds from carbohydrates. Part III. Reaction of D-glucose and D-fructose in slightly acidic, aqueous solution, Acta Chem. Scand. B 30, 397-402.

Rapson, W.H. and Corbi, J.-C. (1964): Colour reversion caused by degradation products of oxidized cellulose, Pulp Paper Mag. Can. 65, T459-T466.

Sarybaeva, R.I., Sultankulova, A.S., Vasilikova, T.V. and Afanasiev, V.A. (1991): Degradation of cellulose in the presence of Lewis acids, Cellulose Chem. Technol. 25(3-4), 199-210.

Scheirs, J., Camino, G. and Tumiatti, W. (2001): Overview of water evolution during the thermal degradation of cellulose, Eur. Polym. J. 37(5), 933-942.

Schmidt, J.A. and Heitner, C. (1993): Use of UV-visible diffuse reflectance spectroscopy for chromophore research on wood fibers: a review, Tappi J. 76(2), 117-123.

Selih, V.S., Strlic, M., Kolar, J. and Philar, B. (2007): The role of transition metals in oxidative degradation of cellulose, Polym. Degrad. Stab. 92(8), 1476-1481.

Sevastyanova, 0., Li, J. and Gellerstedt, G. (2006): On the reaction mechanism of the thermal yellowing of bleached chemical pulps, Nord. Pulp Paper Res. J. 21(2), 188-192.
Shafizadeh, F. and Bradbury, A.G.W. (1979): Thermal degradation of cellulose in air and nitrogen at low temperatures. J. Appl. Polym. Sci. 23(5), 1431-1442. Simão, J.P.F, Egas, A.P.V., Baptista, C.M.S.G., Graca Carvalho, M. and Castro, J.A.A.M. (2005): Evolution of methylglucuronic and hexenuronic acid contents of Eucalyptus globulus pulp during kraft delignification, Ind. Eng. Chem. Res. 44(9), 2990-2996.

Singh, B., Dean, G.R. and Cantor, S.M. (1948): The role of 5-(hydroxymethyl)-furfural in the discoloration of sugar solutions, J. Am. Chem. Soc. 70(2), 517-522.

Stenius, P. (2000): Forest Products Chemistry, Fapet Oy, Helsinki, Finland, p. 54. Strlic, M., Kolar, J., Philar, B., Rychly J. and Matisová-Rychlá, L. (2000): Chemiluminescence during thermal and thermo-oxidative degradation of cellulose, Eur. Polym. J. 36(11), 2351-2358.

Strlic, M., Kolar, J., Philar, B., Rychly J. and Matisová-Rychlá, L. (2001): Initial degradation processes of cellulose at elevated temperatures revisited: chemiluminescence evidence, Polym. Degrad. Stab. 72(1), 157-162.

Tajmir-Riahi, H.A. (1988): Interaction of D-glucose with alkaline earth metal ions. Synthesis, spectroscopic, and structural characterization of $\mathrm{Mg}(\mathrm{II})$ - and $\mathrm{Ca}(\mathrm{II})-\mathrm{D}$ glucose adducts and the effect of metal-ion binding on anomeric configuration of the sugar, Carbohydr. Res. 183(1), 35-46.

Taylor, K.A. and Buchanan-Smith, J.G. (1992): A colorimetric method for the quantification of uronic acids, and a specific assay for galacturonic acid, Anal. Biochem. 201(1), 190-196.

Williams, J.C., Fowler, C.S., Lyon, M.S., and Merrill, T.L. (1977): Metallic catalysts in the oxidative degradation of paper, In: Williams, J.C. (ed.), Preservation of Paper and Textiles of Historic and Artistic Value, Advances in Chemistry Series, No. 164, American Chemical Society, Washington, DC, USA, pp. 37-61.

Withmore, P.M. and Bogaard, J. (1994): Determination of the cellulose scission route in the hydrolytic and oxidative degradation of paper, Restaurato, r 47(1), 26-45. Yu, L., Rae, M. and Ni, Y. (2004): Formation of oxalate from the Mg(OH)2-based peroxide bleaching of mechanical pulps, J. Wood Chem. Technol. 24(4), 341-355.

Manuscript received October 4, 2007 Accepted November 24, 2007 